\section{Dekra bündelt Materialprüfgeschäft}

Mit dem Ziel, die Kräfte in der deutschen Materialprüfsparte zu bündeln, fusionieren Dekra Material Testing (DMT), Duisburg, und Incos, Ingolstadt, sowie W. Hofmann, Allershausen, zur neuen Dekra Incos $\mathrm{GmbH}$.

D ekra hat in den vergangenen Jahren die Sparte „Material Testing \& Inspection“ gezielt aufgebaut. Im Jahr 2012 erfolgten die Übernahmen der In$\cos \mathrm{GmbH}$ sowie der W. Hofmann $\mathrm{GmbH}$, mit der sich die Sparte in Süddeutschland und im Großkundengeschäft etablierte. Der Dekra Materialprüfungsbereich beschäftigt in Deutschland mehr als 270 Mitarbeiter an fünf Standorten.

„Durch das Zusammengehen der drei deutschen Einheiten können wir größere Auftragspakete noch effizienter und mit einheitlichen Qualitätsstandards bearbeiten und sind näher an unseren internationalen Großkunden“, sagt Achim Hetterich, Geschäftsführer der neuen Dekra Incos GmbH mit Hauptsitz in Ingolstadt. „Wir wollen im Stammgeschäft weiter expandieren, zudem werden wir das Angebot an Sonderprüfverfahren ausbauen und dort weitere Marktanteile erobern.“

Selbst entwickelte, innovative Prüfverfahren, die bei den skandinavischen Dekra-Töchtern im Einsatz sind, sollen darüber hinaus im Rahmen der internationalen Expansion europaweit adaptiert werden. Neben der mechanisch-technologischen Materialprüfung ist Dekra Incos spezialisiert auf die zerstörungsfreie Werkstoffprüfung, beispielsweise Durchstrahlungs-, Ultraschall- und Oberflächenrissprüfungen, Dichtheitsund Sichtprüfungen und Sonderprüfverfahren. Darüber hinaus übernimmt das Unternehmen die Inspektion von technischen Anlagen und mechanischen Komponenten, Herstellerabnahmen sowie Bau- und Schweißüberwachungen.

\section{Industrielles}
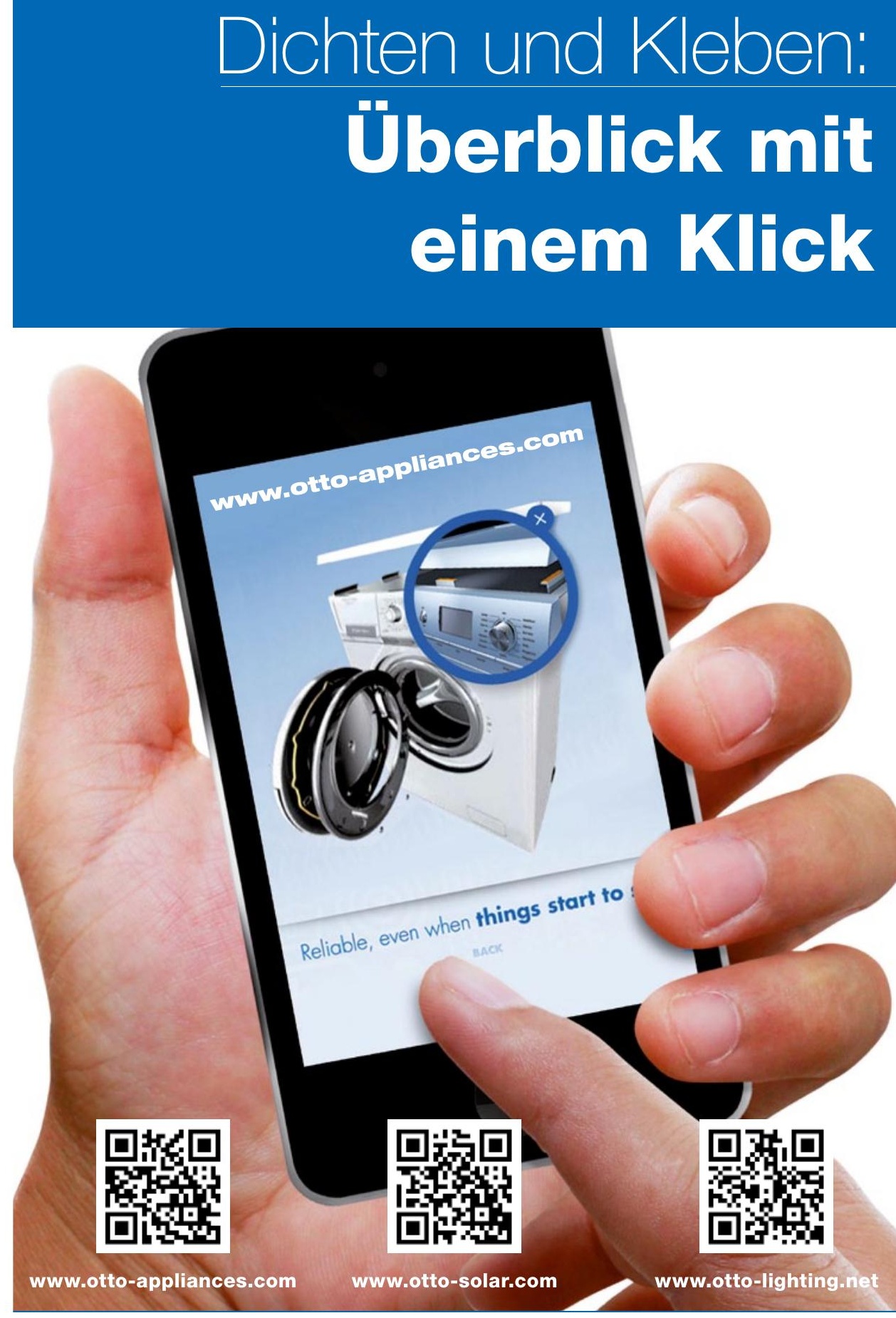

High-tech-Dicht- und Klebstoffe von OTTO übernehmen heute bereits eine Vielzahl von Aufgaben in industriell hergestellten Produkten. Im Internet zeigen wir Ihnen, wo und wie. Surfen Sie doch einfach einmal auf unseren Special-Industries-Websites vorbei. Oder nutzen Sie die QR-Codes für eine schnelle Verbindung via Smart-Phone.

OTTO - Immer eine gute Verbindung! 